\title{
Resilience in Higher Education: A Complex Perspective to Lecturers' Adaptive Processes in Response to the COVID-19 Pandemic
}

\author{
Fabio Bento ${ }^{1, * \mathbb{C}}$, Andréa Giglio Bottino ${ }^{2}$, Felipe Cerchiareto Pereira ${ }^{2}$, Janimayri Forastieri de Almeida ${ }^{2} \mathbb{D}$ and \\ Fabiana Gomes Rodrigues ${ }^{2}$
}

1 Department of Behavioural Science, Faculty of Health Sciences, Oslo Metropolitan University, 0170 Oslo, Norway

2 Faculdade Municipal Miguel Ângelo da Silva Santos-FeMASS, Rua Aluísio da Silva Gomes, Macaé 27930-560, RJ, Brazil; agbottino@gmail.com (A.G.B.); felipecerchi@gmail.com (F.C.P.); janimayri@uol.com.br (J.F.d.A.); fabianagomesrodrigues@gmail.com (F.G.R.)

* Correspondence: fabben@oslomet.no

\section{check for}

updates

Citation: Bento, F.; Giglio Bottino, A.; Cerchiareto Pereira, F.; Forastieri de Almeida, J.; Gomes Rodrigues, F. Resilience in Higher Education: A Complex Perspective to Lecturers' Adaptive Processes in Response to the COVID-19 Pandemic. Educ. Sci. 2021, 11, 492. https://doi.org/ 10.3390/educsci11090492

Academic Editors: James Albright and Han Reichgelt

Received: 12 June 2021

Accepted: 27 August 2021

Published: 1 September 2021

Publisher's Note: MDPI stays neutral with regard to jurisdictional claims in published maps and institutional affiliations.

Copyright: (c) 2021 by the authors. Licensee MDPI, Basel, Switzerland. This article is an open access article distributed under the terms and conditions of the Creative Commons Attribution (CC BY) license (https:// creativecommons.org/licenses/by/ $4.0 /)$.
Abstract: The present article discusses the dynamics of system resilience, focusing on the case of a university college in Brazil. It investigates the experience of lecturers of this educational institution in the initial months of the COVID-19 pandemic. This is exploratory basic qualitative research, aiming at understanding how the university college self-organized in this period. This research focused on local adaptation processes and was conducted through interviews with a sample of lecturers from the study programs offered by the university college. A text analysis software was used to analyze the data generated according to the three aspects of social-ecological resilience. The analytical framework of this research applies the concept of resilience in a socio-ecological system to discuss emergent organizational changes and learning in higher education. Systems resilience highlights adaptation processes characterized by an interplay of previous experience and emerging new knowledge. The findings describe the emergence of new practices and learning as faculty members encountered challenges brought on by the pandemic. Beyond learning new technological tools, the pandemic raised awareness of students' socio-economic backgrounds in the context of inequality in Brazil. However, resilience requires open communication among staff and across organizational levels about adaptation processes that have taken place during the pandemic.

Keywords: higher education; organizational resilience; COVID-19 pandemic; adaptation; complex systems

\section{Introduction}

The goal of the present article is to empirically describe the complex adaptive process of a higher education institution in Brazil in response to the COVID-19 pandemic. The World Health Organization classified the novel coronavirus outbreak as a pandemic in March 2020, and by late April, 166 countries had implemented nation-wide education sector closures affecting $84.5 \%$ of all enrolled learners worldwide, as described by Unesco [1]. Since then, most countries have attempted to gradually reopen their educational institutions. In this context, the overall challenge can be defined as the need to prOVIDe quality education while observing public health policies.

For Gupta et al. [2], there are perceptions of mismatches between (i) available resources and previous experiences with remote teaching practices and technologies; and (ii) the need for online teaching/learning practices. Moreover, the pandemic can be regarded as a major environmental disturbance for educational institutions, highlighting social inequalities and, in many cases, a lack of access to technological resources needed for remote learning. Students from more socially vulnerable groups have been more affected by the pandemic in terms of emotional life and personal circumstances [3]. 
Adaptation processes during the pandemic have involved many organizational challenges. Several studies so far have highlighted educational challenges related to the pandemic [4-6]. Research has highlighted challenges such as the weakness of online teaching infrastructure, the limited exposure of teachers to online teaching, the information gap, a non-conducive environment for learning at home, and inequality in many countries. Pokhrel and Chhetri [7] evaluated the impact of the COVID-19 pandemic on the teaching and learning process across the world. Additionally, this article prOVIDes a comprehensive review on the impact of the COVID-19 pandemic on online teaching and learning as presented in recently published literature [7]. For instance, Leo et al. [8] explore the challenges, opportunities, and implications of the COVID-19 pandemic in the UAE higher education context. This study focuses on the influence of the COVID-19 pandemic on higher education institutions and their responses. It contributes to research on the COVID-19 impact in higher education and the responses, as it describes tools used by higher education universities in the UAE during the spread of COVID-19. It can be considered a pioneer study in the UAE in exploring the relationship between COVID-19 and the higher education field [8].

We hereby aim to contribute to educational research during the pandemic by offering a system resilience perspective to organizational challenges in higher education in the context of the COVID-19 pandemic. Resilience is a concept that originated from the study of socioecological systems and refers to the capacity to "bounce back" from unexpected events and disturbances as suggested by Folke et al. [9]. Resilience is a system's adaptive capacity to rearrange structures and practices in response to either internal failures or environmental changes. The concept highlights learning from encountering the unexpected and the emergence of new knowledge, making the system more prepared for future disturbances. Applying the complex system perspective to higher education institutions requires an understanding of the emergence of learning and new patterns of behavior as outcomes of a rather intricate web of interactions among different agents, and in the context of the exchange of resources between the system and its surrounding environment, as suggested by Bento [10]. We regard the COVID-19 pandemic as a major environmental disturbance, which will be part of the evolutionary history of educational institutions.

Our empirical case is a university college in Brazil that, in 2020, had 62 lecturers and 1207 students attending four undergraduate programs. This is a public and tuition-free institution. As the pandemic reached the municipality where it is located, the university college moved all its educational activities from face-to-face to remote attendance. As of August 2021, it was still not possible to predict when the return to physical attendance would occur.

We present a theoretical framework articulating the concepts of complex systems and socio-ecological resilience. Moreover, we describe our qualitative method approach aimed at grasping lecturers' accounts of experiences related to teaching and organizational changes in the context of the pandemic. Our findings highlight challenges brought by social inequality in Brazil, learning, and adaptations. This prOVIDes the opportunity to discuss management practices aimed at facilitating adaptation processes, and the retention of new knowledge and practices in a post-pandemic scenario.

\section{Literature Review}

The science of complexity looks at social groups as organic-like systems which consist of intricate webs of interactions among interdependent agents [10-13]. Rather than a single unified theory, complexity is a broad development in different scientific areas, highlighting adaptation and non-linearity [14-16]. For Heylighen [17], complex systems have the capacity to self-organize in processes that can never be understood in linear ways. This means that there is a complex interplay of different factors and that small changes in local interactions may escalate to major changes at the system level. We can never fully understand what happens at the system level by simply breaking it into parts and looking at its components isolated from each other. Therefore, the analytical focus in the study of 
complex systems is often on interaction processes instead of individual parts and their properties isolated from their social contexts.

As described by Krispin [18], there are complex webs of feedback among agents that can either restrain or facilitate emergent changes. In complexity studies, feedback consists of sets of interdependent behaviors arranged so that the outputs of one activity becomes the input of a subsequent one. This is therefore an iterative process in complex systems. Such emergent processes can be difficult to predict, as individuals locally and continuously constrain and enable each other's behavior. Change is usually described in terms of a selection of culture requiring variation, the recurrence of constituents upon which feedback loops operate, and a reciprocal relationship between local processes and their external environment.

Previous research about the emergence of novelty in educational practices in higher education have presented cases in which, instead of originating from the idealization of individuals in formal leadership positions, novelty arose from local interaction processes among interdependent individuals [10]. In such cases, formal leaders played the role of recognizing and facilitating emergent processes by giving institutional support and arenas for communication about what was emerging. Such timely interventions can be conceptualized as attempts to facilitate positive feedback loops. Krispin [18] claims that positive feedback loops may emerge spontaneously and without external interference in some complex systems. In such systems, small local changes in initial conditions may lead to changes at the system level. The question that arises at this point is related to the possibilities of facilitating positive feedback loops when these to do not arise spontaneously.

Axelrod and Cohen [11] argue that managing organizations from the perspective of complex systems requires understanding the evolutionary dynamics of interaction, variation, and selection. Higher education institutions, as described by Bento [10], and educational institutions, as described by Aouad and Bento [19] in a broader sense, present important characteristics of complex systems. There are complex webs of interactions that cannot be fully understood by looking at formal organizational structures. There are emergent network structures of interactions among students, lecturers, administrative staff, and managers that change in ways that are difficult to predict. Educational institutions can be seen as systems nested in, and interacting with, broader social, political, and natural systems. Centola [20] demonstrates how the diffusion of new patterns of behavior is related to the existence of both spaces of social reinforcement in network clusters and bridges among these through which rather complex information can spread. Furthermore, for Folke [21] there is a complex exchange of resources with its surrounding environment that affects behaviors and interactions in the systems. The resilience approach to socio-ecological systems emphasizes nonlinear dynamics, unpredictability, and a temporal movement across a period of gradual and radical change.

\subsection{Resilience in Socio-Ecological Systems}

Although most of the literature about system resilience has prOVIDed a normative and prescriptive focus on identifying static characteristics of system resilience, recent studies have approached resilience in terms of system capabilities, as described by Duchek [22]. This means that, rather than identifying static characteristics of resilience, the focus has shifted towards a system's capabilities to anticipate, cope, and adapt in response to perturbations. There is then a focus on processes in a temporal perspective and the emergence of novelty in evolutionary terms.

Folke [21] conceptualizes resilience as a system's capacity to rearrange its structures and the emergence of new patterns of behavior. This is an adaptive capacity that goes beyond absorbing shocks and maintaining functionality, which are characteristics that are usually linked to system robustness. Resilience relates to self-organization, i.e., the emergence of new structures, learning, and the exploration of new possibilities. In systems of interaction among humans, this usually requires facilitating collaborative networks, and a knowledge co-production, as suggested by Berkes [23]. 
Folke [21] (p. 259) highlights central aspects of social-ecological resilience:

- Characteristics: interplay disturbance and reorganization, sustaining, and developing;

- Focus: adaptive capacity, transformability, learning, and innovation; and

- Context: integrated systems feedback and cross-scale dynamic feedback.

As the author suggests, "The resilience approach is concerned with how to persist through continuous development in the face of change and how to innovate and transform into new more desirable configurations" [21] (p. 260). The framework suggested by Folke [21] can be used to investigate organizational resilience in the context of the COVID19 pandemic in a temporal perspective.

Organizational resilience usually involves the co-existence of an informal web of interactions with formal governance processes [24]. Understanding organizational resilience requires uncovering patterns of information flow and behavior that transcend formally designed structures [25]. Moreover, as described by Levin [26], there is the need for management practices that integrate knowledge across different scales and organizational levels. Therefore, there is a temporal movement of interactions across micro and macrolevels [26-29] which are not designed by, but that can be further facilitated by, management practices. Another important characteristic of complex systems is path-dependency, which means that there are multiple thresholds and regime shifts that may lead to different equilibria points for qualitative shifts in system dynamics. Therefore, resilience is hereby conceptualized as a system capability rather than a state or a set of static properties. Resilience is a meta-capability to anticipate, deal with, and actively adapt to environmental perturbations.

Recognizing resilience as a system capability requires identifying interactions as the main unit of analysis. In self-organizing systems, global patterns arise from multiple interactions among agents. In other words, the emergent whole is not only a sum of its individual properties, but qualitatively different from what happens at the local level.

Duchek [22] claims that resilient organizations develop a broad and diverse knowledge base to cope with unexpected events, and this is usually done by facilitating exploration rather than only exploiting already existing knowledge. As described by March [30] (p. 71), "Exploration includes things captured by terms such as search, variation, risk taking, experimentation, play, flexibility, discovery, innovation". Organizations usually make conscious or unconscious choices between these two processes that may sometimes compete for scarce resources. Sandaker [31] explains that organizations face the challenge of matching the complexity of their surrounding environments, which usually implies facilitating variation and thereby exploration. Furthermore, it is important to facilitate interaction across formal organizational units and levels. This is important in order to amplify the base for selection of new behaviors and knowledge necessary to cope with ever-changing environments. The organizational objective of matching the complexity of the environment differs from a focus on standardized process and products, which requires limiting behavioral variation and interaction [31].

The evolutionary perspective towards life implies a historical logic [32] in which there are multiple equilibria points, meaning that there are various possible outcomes out of every set of initial conditions. Path dependency indicates branching and irreversible processes rather than linear historical accounts. As explained by March [32] (p. 43), "Relatively unlikely events, if they occur, change the structure in permanent ways. History is non-recursive, dynamic, and nonlinear".

Furthermore, there are networks of diffusion indicating that in organizational settings, evolutionary processes depend on patterns of connection that can either restrain of facilitate information flow. Thus, for March [32], interventions in organizational history consist of (i) altering the possibilities for transmission, retention, and retrieval of information; (ii) changing the structure of interactions; and (iii) changing the exploration/exploitation balance. In this regard, evolutionary processes can be largely affected by local and timely interventions. 
It is important to observe how emergent changes in response to the pandemic also involve changes in information flow, structures of interactions, and exploration/exploitation.

\subsection{Resilience and Education}

The teacher is seen here as an agent in a complex system. Being a teacher and performing pedagogical activities in the current context, through remote education due to the COVID-19 pandemic, is a great challenge. In addition to planning the classes, creating exercises, elaborating, and correcting the different assessment instruments, the teacher needs to know how to handle, in a satisfactory way, all the platforms that are used to implement their pedagogical work. The teacher also needs to take into account the heterogeneity and cultural diversity of the student group. Often, aspects inherent to structural factors can negatively influence the development of classes, such as power outages, internet instability, feedback problems, lack of accessibility, little financial resources for the acquisition of new equipment, among many other factors.

Given this scenario, it is essential to think about strategies that can foster collaboration among teachers, taking into account the fact that teaching is a profession that demands new requirements and needs. Knowing how to deal with the unknown in contemporary society is one of the biggest challenges, requiring the development of different skills and abilities. Each individual responds differently to aversive situations, and this difference is related to the concept of resilience. Flach [33] was one of the authors who highlighted the discussion on the concept of resilience at the individual level. For him, an individual becomes resilient depending on the ability to identify the pain one is going through, realizing the meaning it has, and supporting it for a certain time until one can resolve this conflict in a constructive way. The term resilience is not only related to psychological factors, but also to physiological and physical factors [33]. In Brazil, research on resilience at the individual level is relatively recent, with the first studies appearing between 1996 and 1998, and the focus of the theme being children exposed to risk factors [34].

According to Garcia [35], resilience can be classified into three categories: emotional, social, and academic. Emotional resilience refers to positive experiences where the subject will find a solution to problems, knowing how to deal with changes and adaptations, in addition to demonstrating feelings of self-efficacy, self-esteem, and autonomy. Social resilience encompasses aspects that are related to feelings of belonging, personal relationships, and supervision of close friends, parents, and family. Academic resilience involves the school, being a place where the ability to solve problems can be acquired with the collaboration of educational agents. As this study deals only with an educational space configured as a higher education institution, the focus will only be on academic resilience.

In view of this educational context, Tardif and Lessard [36] state that it is impossible to have full control of a classroom, since interaction with students is impacted by many possible events. The teaching activity is complex. Many aspects take place at different levels of reality involving the media: physical, biological, psychological, symbolic, individual, social, etc. They also emphasize that teaching work has its particularities, that is, it involves a variety of tasks, requiring professional skills and abilities. In the exercise of teaching, an effective process of change is necessary, being attentive to the new requirements related to the new social context and to the knowledge that is innovated every day. Through so many educational changes, the teacher can develop feelings of anxiety, insecurity, stress, and fear.

\section{Methods}

This study followed a basic qualitative [37] approach, aiming at grasping lecturers' experiences of adaptation processes during the pandemic. The findings prOVIDe the opportunity to discuss learning and complex adaptive processes in one higher education institution. The complexity of organizational settings, characterized by non-linearity and the interplay of often-unexpected factors, permeates our choice of method [38]. The contribution of qualitative research to the complexity sciences consists of exploring, in a 
contextual and temporal perspective [38], the different turning points in the evolutionary history of the social system.

The interview "plot" followed a temporal logic, starting with the participants' initial contact with the pandemic and the awareness that it would reach the everyday life of the university college. The interviewers then brought up questions about the emergence of different practices and learning at different levels, feedback loops, and the possibility of the retention of practices in a post-pandemic scenario.

\subsection{Data Gathering}

Initially, the researchers contacted the senior management of the university college in order to get permission to conduct this study. With permission granted, the college management forwarded an electronic communication to the faculty, informing them that some lecturers would be approached by the researchers.

It was found that the institution had four undergrad programs, engaging around 15 lecturers in each program. It was decided that a sample of $20 \%$ of each course, that is three lecturers, would participate in the interviews, for a total of 12 interviewees. This may be regarded as a limited number which does not prOVIDe the basis for generalization. Furthermore, this may be regarded as a limitation of this study. However, the goal of basic qualitative studies, as such, is not to prOVIDe statistically generalizable data, but to explore, in depth, the experience of participants, prOVIDing the space to understand processes rather than relationships between variables [37]. Furthermore, as highlighted earlier, it prOVIDes the space for identification of the emergence of unexpected factors. Therefore, qualitative studies play an important role in the study of complex systems [38]. This approach also has an exploratory potential by identifying variables that can be further investigated in quantitative studies.

The analytical focus of this study is on the experience of lecturers and did not include other stakeholders. This was a necessary delimitation in the context of this study, but it is important to bear in mind that the experience of other stakeholders, such as students and college managers, could also have prOVIDed important insights into adaptation processes. By highlighting this delimitation, we stress that this study does not prOVIDe a complete description of all the experiences of adaptation processes during the pandemic, but explores, in depth, the experience of participants across the four study programs.

It is important to point out that the research sought to guarantee gender equality among all the interviewees. The selected respondents were contacted by the researchers to assess their interest. If they did not accept the offer to participate in the survey, a new random draw would be held. The selected respondents were informed of the study proposal, that the data collected would be confidential, and would be deleted after the study was concluded. They were presented with the research consent form, a signature was requested, and the best time for the interview was agreed upon. It was explained that, due to sanitary restrictions during the pandemic, the research would be carried out remotely, by means of computer software.

Seven main questions (Appendix A) were raised to the respondents in interviews that lasted between $30 \mathrm{~min}$ and $2 \mathrm{~h}$. The interview guide operationalizes the concept of resilience in socio-ecological systems [18]. Unlike questionnaires usually applied in quantitative research, semi-structured interview guides present open-ended questions, prOVIDing the space for the participants to present their experiences in their own words [39,40]. While this prOVIDes the researcher with less control of the interview situation, it again opens the space for narratives and descriptions as presented by the participant. In basic qualitative studies, there are usually less questions than in quantitative questionnaires. However, the open-ended questions pave the way for a dialogue between the researcher and the participant. In the case of this study, the dialogue followed a temporal logic, covering different aspects of systems resilience [18] as experienced by the participants.

The interviews were conducted in October and November 2020 and recorded for later transcription. 


\subsection{Analysis and Ethics}

The 12 interviews were transcribed and coded with NVivo [41], which is a program that supports the analysis of texts and other forms of qualitative material. The initial analytical step consisted of reading the transcribed material as "raw material", in order to get acquainted with the qualitative material. The data analysis followed a theory-driven logic [32], meaning that the data was coded according to the three overall aspects of socio-ecological system resilience suggested by Folke [21].

The second analytical step consisted of creating a hierarchy of categories and codes operationalizing the concept of socio-ecological resilience.

The following figure illustrates this process:

The interview transcripts were then coded according to the three overall categories and nodes within these as described in Figure 1. The nodes were populated with extracts from interviews that were regarded as indicators of characteristics of organizational resilience. In many ways, the coding process had an interpretive character. However, ongoing dialogue between members of the research teams prOVIDed the opportunity to address possible biases and, thereby, contributing to the internal validity of the analysis.

\section{Nodes}

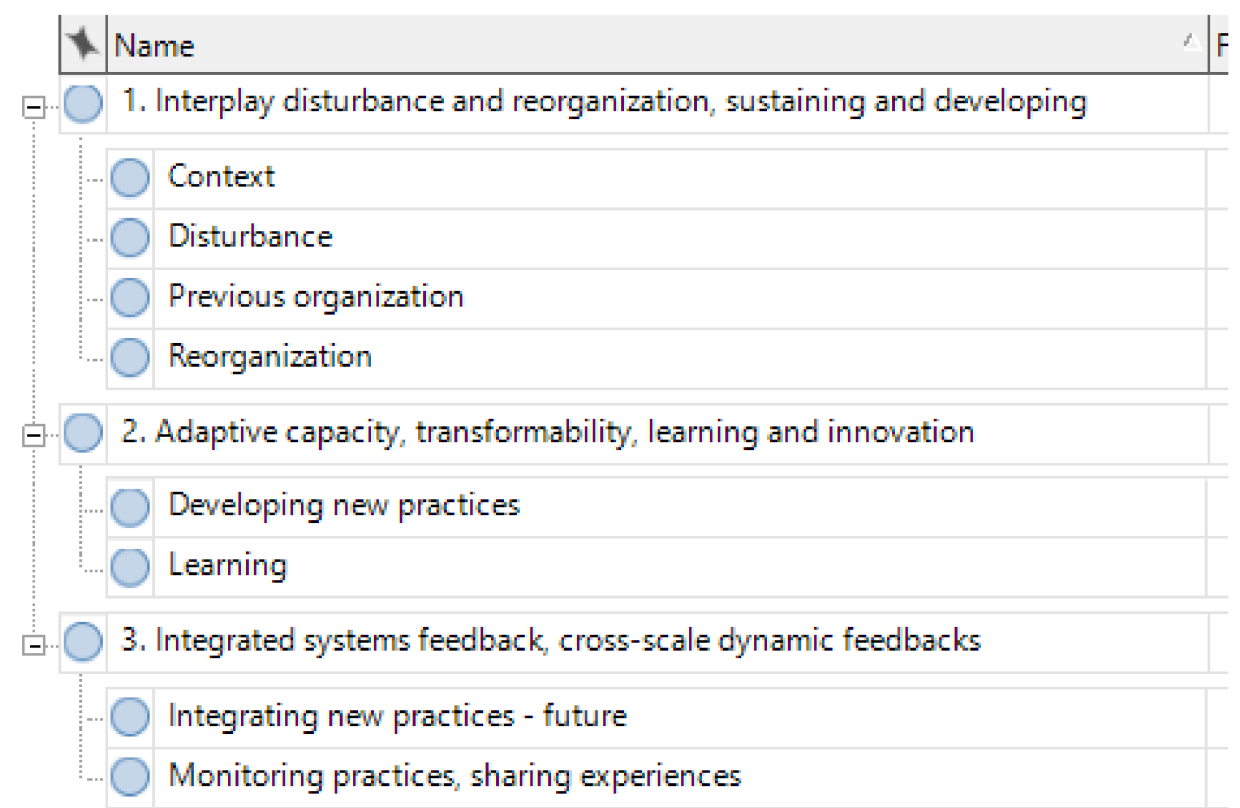

Figure 1. Overall categories and codes (extract from NVivo).

Furthermore, the analysis of experiences of adaptation processes identified three main emergent clusters of findings that are quantitatively presented in Section 4.4. The identification of the clusters of findings followed a data-driven logic [32] that, as such, emerged from the data rather than being guided by theory. Unexpected factors become evident here. We present the quantitative incidence of three main areas of findings across the qualitative accounts of the participants.

The main ethical dimension of this study consisted of protecting the anonymity of the institution and participants. Information about adaptation processes that could possibly identify respondents is not reported in this article.

\section{Results}

This section consists of the presentation of findings in a temporal perspective, articulating central concepts of socio-ecological resilience. 


\subsection{Characteristics: Interplay Disturbance and Reorganization, Sustaining, and Developing}

In March 2020, the university college initially suspended its lectures for two weeks and implemented online teaching thereafter. All participants $(n=12)$ reported that they did not expect at this point that social distancing measures would last for the whole of the 2020 academic year. However, as the pandemic reached the country and the region, the university college moved to full online lecturing. The element of surprise was highlighted by most participants. This initially led to a reorganization of work at different levels, ranging from maintaining communication with the college management, choices of communication platforms, and even domestic adaptations.

For almost all lecturers $(n=10)$, this was their first experience with distance education and, at this initial stage, they received little in terms of guidance from the college management or public authorities. For instance, half the lecturers reported having purchased stationary material, headphones, and even furniture to adapt their private spaces for online lecturing $(n=6)$. This was also a period of initial encounters with contexts of social inequality among students, sometimes resulting in limited knowledge of telecommunication tools and limited internet access.

Table 1 depicts accounts of interplay disturbance and initial adaptation processes in the university college.

Table 1. Interplay disturbance and reorganization, sustaining, and developing.

\begin{tabular}{cc}
\hline Codes & Extracts from Interviews \\
\hline "I first became aware of the situation when physical lectures were cancelled. I thought we \\
would be able to continue in classrooms, even if keeping physical distance, wearing masks, \\
using sanitizers, and so on. I didn't expect that we would ever reach the point that we \\
would have to move lectures to online platforms. It was very sad and painful then." \\
(Participant A) \\
"As I understand, the senior management of the university college had always had a good \\
relationship with the lecturers, and this has been kept during the pandemic. They always \\
listen and give us feedback. This hasn't changed during the pandemic." (Participant A) \\
"I first understood the seriousness of the situation when classes were cancelled. I remember \\
wondering how I would be able to teach Calculus with slides. I got desperate. This was the \\
moment when I realized that I would have to rethink the whole semester, even if my course \\
plan was already being implemented. My strategy simply would not work remotely." \\
(Participant E) \\
Disturbance \\
"Each one of us started creating one's own way of lecturing. I tried to understand the \\
limiting conditions of my students in order to adapt myself to their scarce resources. This \\
was very challenging. Some students lived in remote areas with bad internet coverage, or \\
didn't have a computer suitable to follow online lectures. This was very demanding, but \\
these things started settling down after a while." (Participant B)
\end{tabular}

\subsection{Focus: Adaptive Capacity, Transformability, Learning and Innovation}

In this subsection, descriptions of local adaptation processes, variation, and the exploration of new possibilities are presented. While in the previous subsection all accounts $(n=12)$ described efforts to maintain teaching activities despite a major environmental disturbance, here the accounts illustrate the emergence of novelty in teaching practices. Beyond that, participants narrate interaction processes with students, through which they gained further insight into their socio-economic backgrounds in the context of high inequality in Brazil. The social dimension of education and empathy towards students in these conditions were highlighted by over half $(n=8)$ the participants. In this regard, adaptation processes were far beyond the use of new technological tools, but developing new approaches to teaching, taking into account heterogeneity, poverty, and limited access to technological resources. 
Paradoxical as it may seem, most participants $(n=8)$ described getting more familiar with the students' social environments as teaching moved to digital forms in response to physical distancing measures.

Table 2 illustrates accounts of emerging new practices and learning

Table 2. Adaptive capacity, transformability, learning, and innovation.

Codes

New practices

\section{Extracts from Interviews}

"I understood that I had to improve my classes in order to make these more stimulating and, thereby, facilitating student participation. I have used more games, group dynamics, and questions to individual students during classes" (Participant A)

"I had to adapt my teaching to the restricted access to technological resources and internet faced by many of my students. Some students live in remote areas with bad internet coverage, and some do not even have computers. This was very demanding in the beginning, but we have adapted." (Participant B)

"I had to learn new technological tools and this was very important because otherwise we wouldn't have lectures. Before we would go to the classroom, look at the student and ask them how the class went. Now we can't interact in this way. We have to use more

WhatsApp and now sometimes I receive pictures of assignments from students who need my help. Beyond that, I had to learn to edit videos and use learning platforms beyond simply storing teaching material." (Participant $\mathrm{H}$ )

"The main change here was to see myself in the shoes of the student and to see the situation from their perspective. They have bad internet coverage and sometimes have to send to some of their assignment in a hurry because their data package may expire. Sometimes they have to feed their families while attending lectures. Sometimes there was only one computer for the whole family." (Participant G)

"I had to learn that education goes way beyond the classroom situation. There is the wide social context that we have to understand. I have always tried to use new teaching methods but now I understand much more how heterogeneous my students are." (Participant D)

Learning

"I have learned a lot in relation the social dimensions of education. In a normal classroom situation, we do not observe the same problems. In this new context, although physically distant, we can get closer to the students. Sometimes we realize that we lived in a bubble and that reality is much broader than we thought. I have a closer contact with students now and see how they struggle to pursue a higher education degree due to their economic situation or lack of access to technological resources." (Participant F)

"I learned a lot, but the most important was in terms of empathy. It may sound strange to talk about empathy when we are looking at a computer screen, but the truth is that interacting with students in this context made me realize that they feel the same as us: unsafe and uncertain about the future." (Participant K)

\subsection{Context: Integrated Systems Feedback, Cross-Scale Dynamic Feedbacks}

All participants $(n=12)$ described informal interaction processes among lecturers in which they discussed challenges and practices. However, information/experience-sharing usually took place in the context of small groups of lecturers within each academic program but with little interaction with other groups within the same program, other groups in the university college, or with other organizational levels. This indicates the emergence of informal feedback systems through which lecturers shared experiences related to the pandemic $(n=8)$.

Furthermore, although there were some accounts of interaction and information sharing with/from the university college management, there was not any formal arena to discuss learning or the maintenance of new practices in the future.

Table 3 shows extracts of interviews that account for emerging monitoring mechanisms and reflection upon the integration of new practices 
Table 3. Integrated systems feedback, cross-scale dynamic feedback.

Codes

Monitoring results

Integrating new practices

Extracts from Interviews

“We exchanged experiences as lectures were being conducted. We looked like the students trying to follow online classes. This was our reality: teachers exchanging experiences and trying to adapt new tools. It was nice to see the reciprocity as we were also trying to help each other. I think that distance teaching got us closer, as paradoxical as it may look." (Participant B)

"I had some informal meetings with colleagues but this could have been further explored in the context that we are living. Technology could have been used to promote interaction among us lecturers. This was already difficult before the pandemic. The university college could have created more arenas to discuss experiences during the pandemic." (Participant

B)

"I think that the pandemic created a new momentum for distance teaching and we lecturers will need to prepare ourselves for this new reality. This will not regress." (Participant B)

"Before the pandemic, I would often tell my students: 'This is a technological tool and you have to work it out'. I will not do that anymore. We are not here just to say a few things about Economics or Law. We are here to understand the students" (Participant E)

\subsection{Main Clusters of Findings and Recent Developments}

The analysis of qualitative findings highlights the emergence of innovation/exploration; informal feedback systems in groups in which adaptation was discussed and an increasing awareness of the students' socio-economic background.

These are three main areas of findings, quantitatively illustrated by Table 4:

Table 4. Quantitative description of findings.

\begin{tabular}{ccc}
\hline Areas of Findings. The Emergence of: & Participants & Percentage \\
\hline Exploration/Innovation & 12 & $100 \%$ \\
\hline $\begin{array}{c}\text { Informal feedback systems: groups for } \\
\text { experience sharing/discussions }\end{array}$ & 8 & $66.6 \%$ \\
\hline $\begin{array}{c}\text { Awareness of the students' socio-economic } \\
\text { environment }\end{array}$ & 8 & $66.6 \%$ \\
\hline
\end{tabular}

Further communication with participants after the main data collection period indicates that, after more than a year living with the restriction measures and the online classroom system, it is possible to observe an apparent accommodation of the remote teaching practice, as well as in the institutional procedures. The institution's maintainer standardized the platform for transmitting online classes through the acquisition of a communication service, still in place in the second semester of 2021. Throughout this period, the adaptation of the teachers' practices and teaching methods were still perceived by participants. All teachers were able to carry out exam grading as foreseen in the calendar, and finalize their subjects in the two semesters of 2020 and in the first semester of 2021 without any delays or any further complications. The institution, albeit in a virtual way, conferred a degree on graduating students, carrying out online graduation ceremonies in both periods, and is expected to be conducted in the same format for the first period of 2021. The submissions and evaluations of bachelor's monographies took place with pleasant news of the positive repercussions of some of these works beyond the borders of the institution.

In another aspect, the pandemic claimed the lives of staff at the institution and their relatives, in addition to affecting others. There was a loss of human capital and the emergence of mourning acts related to it. The risk of contagion reverberated throughout the institution, generating examples of solidarity and belonging. On the other hand, the moment of condolence drew attention to problems, such as communication and institutional interaction, that still need to be verbalized collectively. 


\section{Discussion}

The overall goal of the present study is to explore the processes of local adaption in one higher education institution in Brazil in response to the COVID-19 pandemic. An analysis of the qualitative interviews illustrates the lecturers' individual adaptation processes and the emergence of a myriad of teaching practices. For many participants, new teaching practices involved not only the adoption of new technological tools but also a further recognition of the socio-economic background of their students. Findings are hereby discussed looking at adaptation processes from a systems perspective.

\subsection{Lecturers' Adaptive Processes}

The results obtained through the research, with regard to learning, corroborate what Garcia [33] highlights about resilience, which can be classified into three categories: emotional, social, and academic. Emotional resilience refers to positive experiences where the subject finds a solution to problems, know how to deal with changes and adaptations, in addition to demonstrating feelings of self-efficacy, self-esteem, and autonomy. In this sense, this idea is included in participant K's speech, as he needed to have empathy in the face of the new situation. Empathy involves an emotional ability to interpret the psychological states of others. It is also considered an aspect of interpersonal communication that is predominantly emotional. Furthermore, according to Garcia [35], social resilience encompasses aspects that are related to the feeling of belonging, personal relationships, and supervision of close friends, parents, and family. Starting from this first, participant F related to the concept of social resilience, considering that the teacher had a personal relationship with his students, where he reported that he learned a lot in relation to the social dimension of education, as in a normal situation in the classroom the same problems were not observed and that, in this new context, although physically distant, the teacher gets closer to the students, establishing a social relationship. In addition, the experience reported by participant F corroborates what Tardif and Lessard [36] emphasize, that is, that teaching work has its particularity, involving a variety of tasks, requiring professional skills and personal abilities. In the exercise of teaching, an effective process of change is necessary, being aware of the new requirements related to the new social context and knowledge that is innovated every day. Through so many educational changes, the teacher can develop feelings of anxiety, insecurity, stress, and fear. These feelings were expressed when participant $\mathrm{F}$ reported that he sometimes realizes that he is living in a bubble, and that reality is much broader than previously thought; that is, anxiety, insecurity, stress, and fear are explicit in this statement. It should be noted that when talking about insecurity, it is also possible to consider the fears of the future related to the teaching practice that will come.

\subsection{System Level Resilience in Higher Education}

As the local government and the university college prOVIDed little guidance in terms of how to approach this context, it is possible to observe self-organizing processes, which involved variation in terms of educational practices beyond the adoption of new communication tools. Self-organization is indeed an important feature of complex adaptive systems as previously highlighted in the conceptual framework of this study [15-17]. Likewise, variation linked to the exploration of new possibilities is required for system level adaptation $[18,30,31]$ and resilience. The emergence of exploration and innovative practices was described by all participants. Such findings also resonate with previous research, describing that, often, innovation in teaching practices in higher education is the outcome of emergent processes rather than central or external design [10]. For instance, participant $\mathrm{H}$ described the need to innovate due to circumstances. Likewise, as participant A described, there was a need to improve online lectures to make them more stimulating and to facilitate student participation. This demonstrates the effects of emerging processes such as the pandemic crisis. The aspect of variation in adaptive processes needs to be highlighted here, as the innovative process differed among the participants. In other words, 
an analysis of the interviews shows the emergence of various practices at the individual level.

On the other hand, understanding emergence in complex systems involves looking beyond individual processes and properties, thereby understanding interaction among constituents. In other words, system resilience also involves positive feedback loops, recurrence of behavior, and reciprocity between emergent practices and the surrounding environment [18]. System resilience capability as described by Duchek [22] lays not only on individual adaptive processes but on the communication processes enabling the capacity to cope and rearrange its own structures in response to environmental changes. Bearing that in mind, it is possible to raise questions about the integration of new practices and what trends may be accelerated in the post-pandemic future. This need is observed in participant B's description, when he points out the absence of institutional arenas for communication and exchange of experiences. Most participants $(n=8)$ reported engaging in informal emergent discussion groups in which they shared experiences during the pandemic. This can be interpreted as the emergence of an informal feedback system, albeit highly divided into silos. However, a lack of communication across informal groups and organizational levels may hinder the emergence of new patterns of behavior at the system level.

From a management perspective, there is the need to open communication channels and arenas for discussion about experiential knowledge gained during the pandemic and information about practices develop during this period. This can potentially facilitate positive feedback loops in the form of institutional support and social reinforcement across peers in relation to innovative practices. Furthermore, the endurance of emergent practices is also related to reciprocity [18] with the surrounding environment. This raises questions about policies that recognize emergent practices and promotes communication about these across higher education institutions and society in general.

Resilience depends on informal network structures that either facilitate or limit social contagion in the form of the diffusion of new practices [20]. As argued earlier, facilitating communication across groups that contribute to consolidated cross-scale feedback relates to resilience [21]. In this regard, further research can benefit from the application of social network analysis [42-44] as a research method to uncover the structure of emergent webs of interaction and communication barriers. Self-organization, in this COVID context, was presented as a common practice among teaching professionals by means of the gap created between occurrences and formal orientations on educational practices coming from the management of educational organizations.

\section{Conclusions}

Much of the public debate about education during the new coronavirus pandemic has focused on the implementation and effects of policies adopted at the government level. However, from the perspective of complex systems, it is important to look at the emergence of several new patterns of behavior in educational settings. This qualitative study reveals experiences from teachers of adaptive processes beyond the choice and adoption of technological tools. Participants' accounts indicate variation in behavior, exploration, changes in interactions between teachers and students, and emergence in the context of rapid and unexpected environmental instability that brought about the pandemic. We contribute to the study of higher education responses during the pandemic by presenting living accounts of emergent adaptation processes beyond formal processes and structures. Nevertheless, the selection and durability of innovative practices in a postpandemic future will depend on feedback loops in very complex networks of interaction that can either allow or constrain evolutionary change.

Future research will benefit from understanding the evolution of emerging networks of interaction in complex systems. Further studies can also benefit from exploring the experience of other stakeholders in higher education, such as students, managers, and policy makers. In this sense, it is worth reflecting on the next steps for higher education institutions and, particularly, how these next steps can be managed or facilitated. 
There are clearly important gains in the teaching practices of education professionals that, if not shared and discussed at the institutional level, can be lost in a way that is harmful to the evolution of academic training. For instance, from a pedagogical perspective, a further awareness of students' social environment and background may inform innovative practices. For a more in-depth study, it is necessary to know how structures for network cooperation and dissemination of new practices in higher education institutions are being developed. This will require an investigation of interactions focusing on everyday patterns of interaction and information flow. It is also important to observe the established practices in these institutions for the dissemination of the skills developed, and to understand the role of managers and professionals in sharing experiences. This diagnosis can reveal to managers the importance of developing certain skills to support professionals and prOVIDe the collective with new perspectives for conducting higher education. In addition to the skills of professionals and managers, it is necessary to develop management and policy interventions with the aim of enabling positive feedback loops that facilitate the exploration of new possibilities.

Author Contributions: Conceptualization, F.B., A.G.B. and J.F.d.A.; Formal analysis; F.B., A.G.B., F.C.P., J.F.d.A. and F.G.R.; APC funding acquisition, F.B.; Investigation, A.G.B., F.C.P., J.F.d.A. and F.G.R.; Methodology, F.B., A.G.B., F.C.P., J.F.d.A. and F.G.R.; Project administration, F.B.; Writingoriginal draft, F.B., A.G.B., F.C.P., J.F.d.A. and F.G.R.; Writing-review \& editing, F.B., A.G.B., F.C.P., J.F.d.A. and F.G.R. All authors have read and agreed to the published version of the manuscript.

Funding: This research received no external funding. The APC was funded by OsloMet.

Institutional Review Board Statement: The study was conducted according to the guidelines of the Declaration of Helsinki, and approved by the Norwegian Centre for Research Data. Project Reference: 574785 .

Informed Consent Statement: Informed consent was obtained from all participants.

Data Availability Statement: Due to privacy reasons and confidentiality, the data are not publicly available. Queries about data availability may be directed to the corresponding author.

Conflicts of Interest: The authors declare no conflict of interest.

\section{Appendix A}

Interview Guide:

1. What was the moment that you became aware that the pandemic would bring implications for your activity as a lecturer?

2. How did it change educational practices?

3. What changes in interaction with students did you experience?

4. What did you learn in this period?

5. How was your interaction with colleagues in this period? Did you have the opportunity to discuss/share experiences?

6. And with the university college management?

7. How do you expect that this experience will bring changes to your activity as a lecturer in the future, post-pandemic?

\section{References}

1. Unesco. Education Response. 2020. Available online: https://en.unesco.org/covid19/educationresponse (accessed on 1 August 2021).

2. Gupta, M.M.; Jankie, S.; Pancholi, S.S.; Talukdar, D.; Sahu, P.K.; Sa, B. Asynchronous Environment Assessment: A Pertinent Option for Medical and Allied Health Profession Education during the COVID-19 Pandemic. Educ. Sci. 2020, 10, 352. [CrossRef]

3. Aristovnik, A.; Keržič, D.; Ravšelj, D.; Tomaževič, N.; Umek, L. Impacts of the COVID-19 Pandemic on Life of Higher Education Students: A Global Perspective. Sustainability 2020, 12, 8438. [CrossRef]

4. Peimani, N.; Kamalipour, H. Online Education and the COVID-19 Outbreak: A Case Study of Online Teaching during Lockdown. Educ. Sci. 2021, 11, 72. [CrossRef] 
5. Müller, A.M.; Goh, C.; Lim, L.Z.; Gao, X. COVID-19 Emergency eLearning and Beyond: Experiences and Perspectives of University Educators. Educ. Sci. 2021, 11, 19. [CrossRef]

6. Adov, L.; Mäeots, M. What Can We Learn about Science Teachers' Technology Use during the COVID-19 Pandemic? Educ. Sci. 2021, 11, 255. [CrossRef]

7. Pokhrel, S.; Chhetri, R. A Literature Review on Impact of COVID-19 Pandemic on Teaching and Learning. High. Educ. Future 2021, 8, 133-141. [CrossRef]

8. Leo, S.; Alsharari, N.M.; Abbas, J.; Alshurideh, M.T. From Offline to Online Learning: A Qualitative Study of Challenges and Opportunities as a Response to the COVID-19 Pandemic in the UAE Higher Education Context. In The Effect of Coronavirus Disease (COVID-19) on Business Intelligence; Alshurideh, M., Hassanien, A.E., Masa'deh, R., Eds.; Springer: Cham, Switzerland, 2021; Volume 334, pp. 203-217.

9. Folke, C.; Hahn, T.; Olsson, P.; Norberg, J. Adaptive governance of social-ecological systems. Annu. Rev. Environ. Resour. 2005, 30, 441-473. [CrossRef]

10. Bento, F.C. The contribution of complexity theory to the study of departmental leadership in processes of organisational change in higher education. Int. J. Complex. Leadersh. Manag. 2011, 1, 275. [CrossRef]

11. Axelrod, R.; Cohen, M.D. Harnessing Complexity; Basic Books: New York, NY, USA, 2001.

12. Holland, J.H. Complex adaptive systems. Daedalus 1992, 121, 17-30.

13. Holland, J.H. Hidden Order: How Adaptation Builds Complexity; Addison-Wesley: Boston, MA, USA, 1995.

14. Waldrop, M.M.; Stein, D. Complexity: The Emerging Science at the Edge of Order and Chaos. Phys. Today 1992, 45, 83. [CrossRef]

15. Preiser, R. Identifying general trends and patterns in complex systems research: An overview of theoretical and practical implications. Syst. Res. Behav. Sci. 2019, 36, 706-714. [CrossRef]

16. De Domenico, M.; Brockmann, D.; Camargo, C.Q.; Gershenson, C.; Goldsmith, D.; Jeschonnek, S.; Lorren, K.; Nichele, S.; Nicolás, J.R.; Schmickl, T.; et al. Complexity Explained. 2019. Available online: https:/ / ore.exeter.ac.uk/repository/bitstream/handle/10 871/124302/ComplexityExplained.pdf?sequence=1 (accessed on 1 August 2021).

17. Heylighen, F. The science of self-organization and adaptivity. Encycl. Life Support Syst. 2001, 5, $253-280$.

18. Krispin, J.V. Positive Feedback Loops of Metacontingencies: A New Conceptualization of Cultural-Level Selection. Behav. Soc. Issues 2017, 26, 95-110. [CrossRef]

19. Aouad, J.; Bento, F. A Complexity Perspective on Parent-Teacher Collaboration in Special Education: Narratives from the Field in Lebanon. J. Open Innov. Technol. Mark. Complex. 2019, 6, 4. [CrossRef]

20. Centola, D. How Behavior Spreads: The Science of Complex Contagions; Princeton University Press: Princeton, NJ, USA, 2018; Volume 3.

21. Folke, C. Resilience: The emergence of a perspective for social-ecological systems analyses. Glob. Environ. Chang. 2006, 16, 253-267. [CrossRef]

22. Duchek, S. Organizational resilience: A capability-based conceptualization. Bus. Res. 2020, 13, 215-246. [CrossRef]

23. Berkes, F. Environmental Governance for the Anthropocene? Social-Ecological Systems, Resilience, and Collaborative Learning. Sustainability 2017, 9, 1232. [CrossRef]

24. Walker, B.; Gunderson, L.; Kinzig, A.; Folke, C.; Carpenter, S.; Schultz, L. A handful of heuristics and some propositions for understanding resilience in social-ecological systems. Ecol. Soc. 2006, 11, 13. [CrossRef]

25. Peters, D.P.; Bestelmeyer, B.T.; Turner, M.G. Cross-scale interactions and changing pattern-process relationships: Conse-quences for system dynamics. Ecosystems 2007, 10, 790-796. [CrossRef]

26. Levin, S. Ecosystems and the Biosphere as Complex Adaptive Systems. Ecosystems 1998, 1, 431-436. [CrossRef]

27. Folke, C.; Carpenter, S.R.; Walker, B.; Scheffer, M.; Chapin, T.; Rockström, J. Resilience Thinking: Integrating Resilience, Adaptability and Transformability. Ecol. Soc. 2010, 15. [CrossRef]

28. Morrison, K. Educational Philosophy and the Challenge of Complexity Theory. Educ. Philos. Theory 2008, 40, 19-34. [CrossRef]

29. Olsson, P.; Folke, C.; Berkes, F. Adaptive Comanagement for Building Resilience in Social? Ecological Systems. Environ. Manag. 2004, 34, 75-90. [CrossRef]

30. March, J.G. Exploration and Exploitation in Organizational Learning. Organ. Sci. 1991, 2, 71-87. [CrossRef]

31. Sandaker, I. A Selectionist Perspective on Systemic and Behavioral Change in Organizations. J. Organ. Behav. Manag. 2009, 29, 276-293. [CrossRef]

32. March, J. The evolution of evolution. In Evolutionary Dynamics of Organizations, 1st ed.; Baum, J., Singh, J., Eds.; Oxford University Press: Oxford, UK, 1994; pp. 39-49.

33. Flach, F.F. Resilience: The Art of Being Flexible; Saraiva: São Paulo, Brazil, 1991.

34. Souza, M.T.S.; Cerveny, C.M.O. Psychological resilience: Literature review and analysis of scientific production. Inter-Am. J. Psychol. 2006, 40, 119-126.

35. Garcia, I. Vulnerability and resilience. Lat. Am. Adolesc. 2001, 2, 128-130.

36. Tardif, M.; Lessard, C. Teaching Work: Elements for a Theory of Teaching as a Profession of Human Interactions; Vozes: Petrópolis, Brazil, 2005.

37. Merriam, S. Introduction to qualitative research. In Qualitative Research in Practice. Examples for Discussion and Analysis, 1st ed.; Jossey-Bass: San Francisco, CA, USA, 2002; pp. 3-17. 
38. Tsoukas, H.; Hatch, M.J. Complex Thinking, Complex Practice: The Case for a Narrative Approach to Organizational Complexity. Hum. Relat. 2001, 54, 979-1013. [CrossRef]

39. Bryman, A. Social Research Methods, 5th ed.; Oxford University Press: Oxford, UK, 2016.

40. Kvale, S. Doing Interviews; Sage: London, UK, 2008.

41. Gibbs, G.R. Qualitative Data Analysis: Explorations with NVivo, 1st ed.; Open University: Philadelphia, PA, USA, 2002.

42. Scott, J. Social Network Analysis, 3rd ed.; Sage: London, UK, 2013.

43. Parise, S. Knowledge Management and Human Resource Development: An Application in Social Network Analysis Methods. Adv. Dev. Hum. Resour. 2007, 9, 359-383. [CrossRef]

44. Borgatti, S.P.; Mehra, A.; Brass, D.J.; Labianca, G. Network Analysis in the Social Sciences. Science 2009, 323, 892-895. [CrossRef] [PubMed] 